\title{
Variation process in stiffness inferred by nonlinear inversion during mainshocks at Kushiro Port vertical array site
}

\author{
Mostafa Thabet ${ }^{1}$, Hiroo Nemoto ${ }^{2}$, and Koichi Nakagawa ${ }^{1}$ \\ ${ }^{1}$ Department of Geosciences, Graduate School of Science, Osaka City University, Osaka, Japan \\ ${ }^{2}$ School of Math and Natural Science, J. F. Oberlin University, Tokyo, Japan
}

(Received July 20, 2007; Revised December 24, 2007; Accepted February 12, 2008; Online published July 4, 2008)

\begin{abstract}
In the present study, a set of three strong motions accompanied by 21 before and after mainshock motions from liquefied soil at the Kushiro Port vertical array site have been obtained. $S$-wave velocity variation is estimated using a new proposed nonlinear GA inversion technique. This inversion technique is reproductive in assessment for $S$-wave velocities due to its direct link with the simulation FEM program and matching technique between the observed and simulated waveforms. Layers ( $6 \sim 23 \mathrm{~m}$ depth) have been found to be responsible for liquefaction at the Kushiro Port site. Stiffness degradation due to liquefaction could be predicted by applying the inversion technique on the horizontal components of the mainshocks at different time-windows and then multiplying the weighting functions by the nonlinear simulated ground motions. These weighting functions were applied to delete the misfit time window of the nonlinear simulated ground motions when these were compared to the observed records. Finally, stacking was applied for the weighted nonlinear simulated ground motions. A strong degree of liquefaction is concluded during the Kushiro-Oki (1993) and the Hokkaido Toho-Oki (1994) earthquakes, whereas a low degree of liquefaction was detected to have occurred during the Tokachi-Oki (2003) earthquake due to high increase of rigidity following a trend that resembles a consolidation curve.
\end{abstract}

Key words: Strong motions, Kushiro Port vertical array site, stiffness degradation, nonlinear inversion.

\section{Introduction}

Analysis of the observed ground motion during or immediately after an earthquake forms the backbone of the development of earthquake monitoring and early damage assessment systems. Ground motion parameters from liquefiedsoil sites have been examined in a number of studies which have employed several methods for assessing liquefaction based on strong motion records. Nakayama et al. (1998), Miyajima et al. (1998), Ozaki (1999), and Kostadinov and Yamazaki (2001) reported various methods that consider ground motion parameters such as peak horizontal ground acceleration, maximum spectrum intensity, and maximum horizontal ground displacement. The respective method evaluates the occurrence of liquefaction either positively or negatively if these parameters exceed certain limit values.

Since the nonlinear effect typically occurs in unconsolidated soft soils, our analysis should be focused on very surficial layers. In this study, modification of subsurface stiffness structure associated with successive mainshocks at Kushiro Port were examined using a newly developed genetic algorithm inversion technique. This technique is able to assess the occurrence of liquefaction through an evaluation of stiffness degradation during strong shaking. It is therefore possible to identify the nonlinear behavior and changes in the physical properties in the layers with the lapsed time. The results are discussed in detail and com-

Copyright (c) The Society of Geomagnetism and Earth, Planetary and Space Sciences (SGEPSS); The Seismological Society of Japan; The Volcanological Society of Japan; The Geodetic Society of Japan; The Japanese Society for Planetary Sciences; TERRAPUB pared with the observed records.

\section{Data}

Kushiro City is a medium-sized city located on the eastern part of Hokkaido, Japan. As shown in Fig. 1, the lithology at Kushiro Port downhole array site can be divided to four main units. (1) coarse sand layers intercalated with thin sandy gravel layers ( $0 \mathrm{~m} \sim 22 \mathrm{~m}$ depth), (2) fine sand layers intercalated with silt layers $(22 \mathrm{~m} \sim 46 \mathrm{~m}$ depth $)$, (3) sandy gravel layers intercalated with coarse sand layers (46 m $~ 52 \mathrm{~m}$ depth), and (4) fine sand layers intercalated with coarse sand layers (52 $\mathrm{m} \sim 77.45 \mathrm{~m}$ depth).

Records of the three mainshocks-the 1993 KushiroOki, the 1994 Hokkaido Toho-Oki, and the 2003 TokachiOki earthquakes - accompanied with 21 before and after mainshocks observed at depths of $0 \mathrm{~m}$ and $77.45 \mathrm{~m}$ were obtained from the Port and Airport Research Institute, as shown in Table 1. The data were recorded using the digital ERS-GV strong-motion seismograph as acceleration with Gal units, with a sampling frequency of $100 \mathrm{~Hz}$. The epicenter locations for these events are shown in Fig. 2 with their hypocenter distribution. In the present study, we focus on the role of the $S$-waves in the horizontal components of all events. By applying Snell's law, we were able to calculate incident angles for all the events using the Koketsu et al. (2003) velocity structure. Therefore, vertical propagation for the seismic waves is assumed because the incidence angles for all the events lie between $88.2^{\circ} \sim 89.8^{\circ}$. 


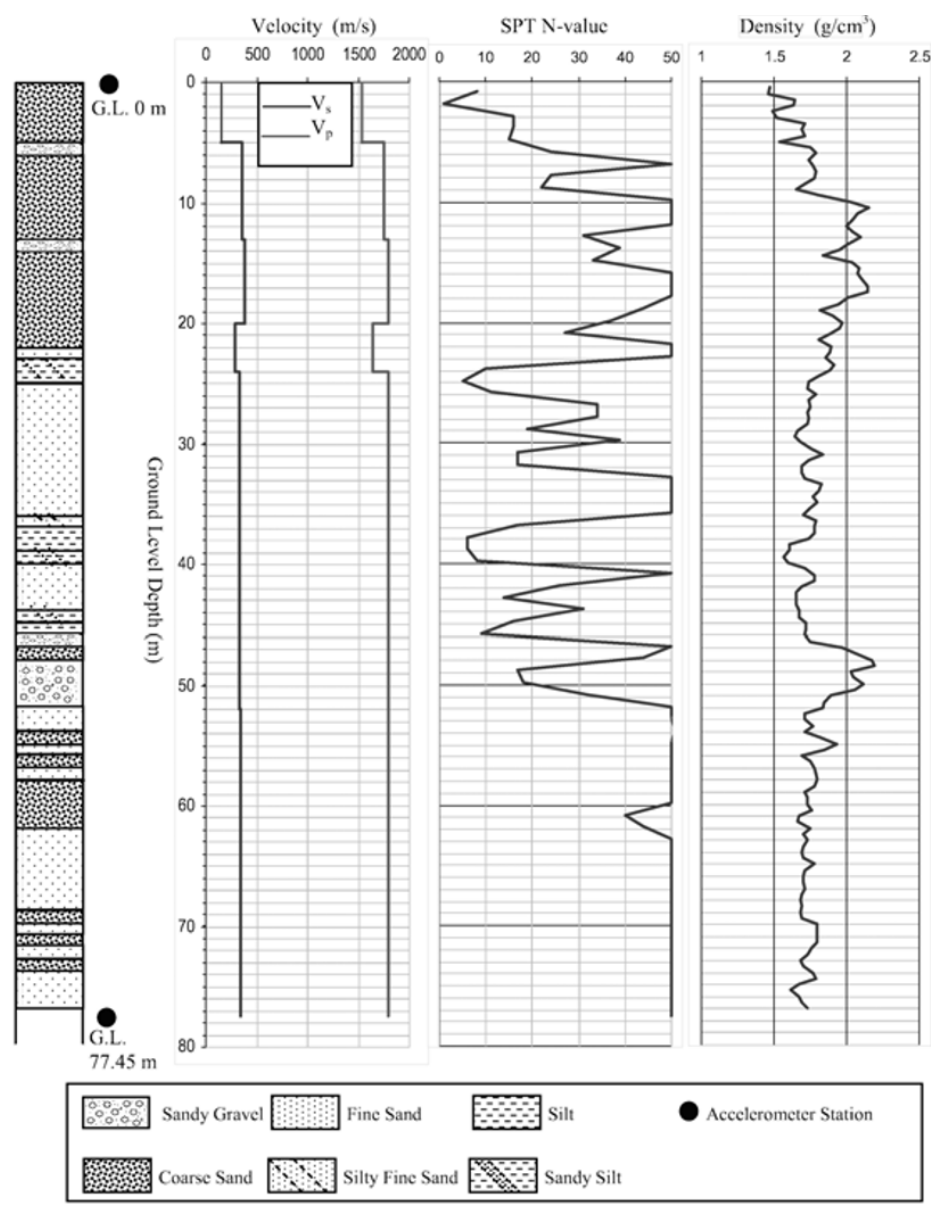

Fig. 1. Soil properties at Kushiro Port vertical array site. $V_{p}$ and $V_{s}$ are the primary and shear wave velocities, respectively.

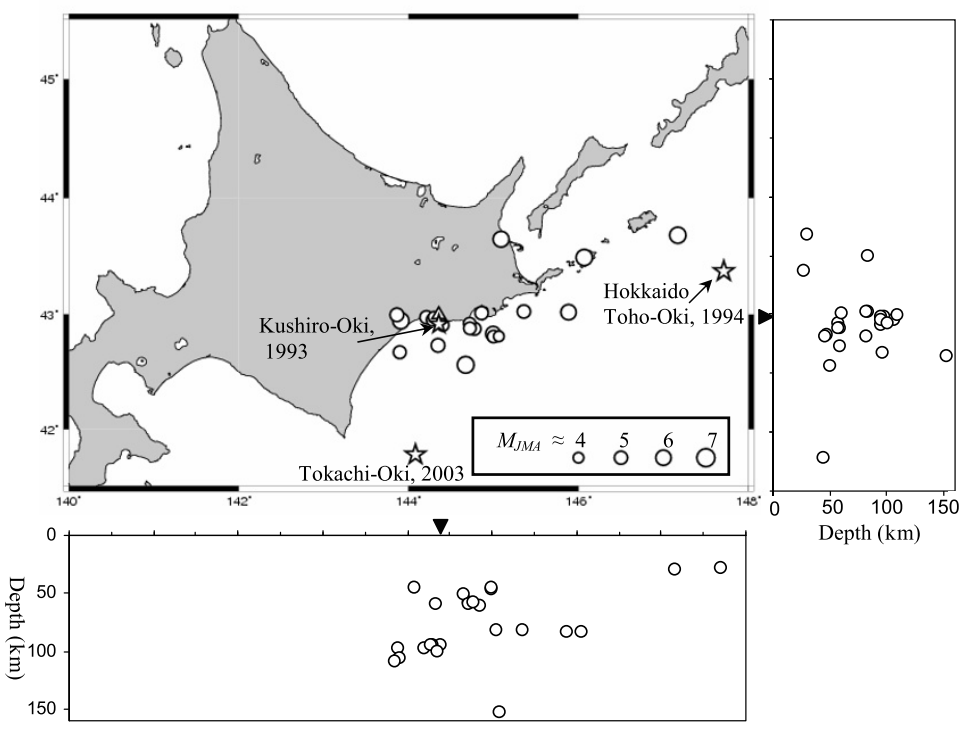

Fig. 2. Epicenter location for events shown in Table 1 with their hypocenter distribution. The triangle, star and circle denote the Kushiro Port vertical array site, mainshock and before or after mainshock event, respectively.

\section{Nonlinear Inversion Technique}

Genetic algorithms (GA) have proven themselves as reliable computational search and optimization procedures for complex objectives invloving large number of variables. In the present study, the objective function for the GA inversion comprises of two main successive steps. Firstly, simulations are conducted by AMPLE2000 (a one-dimensional finite element method based dynamic analysis code, after 
Table 1. Groundmotions recorded at Kushiro Port array site.

\begin{tabular}{|c|c|c|c|c|c|}
\hline Origin time & Latitude & Longitude & Depth $(\mathrm{km})$ & Magnitude & Epicentral distance $(\mathrm{km})$ \\
\hline $5 / 19 / 2005 \quad 1: 33$ & $42^{\circ} 55.2^{\prime}$ & $144^{\circ} 43.2^{\prime}$ & 58.2 & 4.8 & 30.5 \\
\hline $3 / 12 / 2005 \quad 3: 47$ & $43^{\circ} 00.7^{\prime}$ & $144^{\circ} 51.6^{\prime}$ & 61 & 5.1 & 40.7 \\
\hline $4 / 12 / 2004 \quad 3: 06$ & $42^{\circ} 49.9^{\prime}$ & $144^{\circ} 59.7^{\prime}$ & 47 & 5.8 & 54.7 \\
\hline $10 / 8 / 2003$ 18:06 & $42^{\circ} 33.8^{\prime}$ & $144^{\circ} 40.4^{\prime}$ & 51 & 6.4 & 54.5 \\
\hline 9/27/2003 17:06 & $42^{\circ} 44.0^{\prime}$ & $144^{\circ} 20.8^{\prime}$ & 59 & 5.2 & 29.2 \\
\hline $9 / 26 / 2003 \quad 8: 11$ & $42^{\circ} 48.6^{\prime}$ & $145^{\circ} 00.0^{\prime}$ & 46 & 4.8 & 56 \\
\hline $9 / 26 / 2003 \quad 4: 50$ & $41^{\circ} 46.6^{\prime}$ & $144^{\circ} 04.9^{\prime}$ & 45 & 8 & 137.4 \\
\hline $9 / 11 / 2003 \quad 4: 31$ & $42^{\circ} 40.4^{\prime}$ & $143^{\circ} 53.7^{\prime}$ & 97 & 4.9 & 52.1 \\
\hline $4 / 27 / 2001 \quad 2: 48$ & $43^{\circ} 01.2^{\prime}$ & $145^{\circ} 52.9^{\prime}$ & 83.1 & 5.9 & 123.7 \\
\hline $6 / 13 / 2000 \quad 1: 54$ & $42^{\circ} 52.8^{\prime}$ & $144^{\circ} 43.3^{\prime}$ & 58.8 & 4.7 & 32.1 \\
\hline $5 / 13 / 1999 \quad 2: 59$ & $42^{\circ} 56.7^{\prime}$ & $143^{\circ} 54.5^{\prime}$ & 106 & 6.3 & 39.5 \\
\hline 11/15/1997 16:05 & $43^{\circ} 38.8^{\prime}$ & $145^{\circ} 05.3^{\prime}$ & 153.1 & 6.1 & 93.3 \\
\hline $6 / 15 / 199713: 54$ & $42^{\circ} 58.6^{\prime}$ & $144^{\circ} 12.7^{\prime}$ & 97.6 & 5.1 & 12.2 \\
\hline 5/ 6/1996 17:21 & $42^{\circ} 54.4^{\prime}$ & $144^{\circ} 24.2^{\prime}$ & 94.8 & 4.5 & 10.5 \\
\hline $9 / 16 / 1995 \quad 8: 52$ & $42^{\circ} 59.9^{\prime}$ & $143^{\circ} 51.7^{\prime}$ & 109.7 & 5.2 & 40.4 \\
\hline $10 / 6 / 1994 \quad 5: 39$ & $43^{\circ} 40.9^{\prime}$ & $147^{\circ} 10.2^{\prime}$ & 30 & 6.3 & 239.5 \\
\hline 10/ 4/1994 22:22 & $43^{\circ} 22.3^{\prime}$ & $147^{\circ} 42.7^{\prime}$ & 28 & 8.2 & 274.6 \\
\hline 8/31/1994 18:07 & $43^{\circ} 29.4^{\prime}$ & $146^{\circ} 04.1^{\prime}$ & 83.6 & 6.3 & 148.8 \\
\hline 6/ 3/1993 17:01 & $42^{\circ} 48.7^{\prime}$ & $145^{\circ} 03.7^{\prime}$ & 81.6 & 4.1 & 60.7 \\
\hline $3 / 31 / 1993 \quad 6: 43$ & $43^{\circ} 01.6^{\prime}$ & $145^{\circ} 21.4^{\prime}$ & 82.8 & 5.1 & 81.1 \\
\hline $3 / 12 / 1993 \quad 1: 27$ & $42^{\circ} 58.7^{\prime}$ & $144^{\circ} 17.8^{\prime}$ & 95.2 & 4.3 & 5.5 \\
\hline 2/ 4/1993 23:43 & $42^{\circ} 57.2^{\prime}$ & $144^{\circ} 16.9^{\prime}$ & 94.7 & 4.8 & 7.9 \\
\hline 1/15/1993 20:06 & $42^{\circ} 55.0^{\prime}$ & $144^{\circ} 21.4^{\prime}$ & 100.6 & 7.5 & 8.8 \\
\hline $11 / 30 / 1992 \quad 9: 20$ & $42^{\circ} 52.6^{\prime}$ & $144^{\circ} 46.6^{\prime}$ & 57.6 & 4.9 & 36.4 \\
\hline
\end{tabular}

Pestana and Nadim, 2000). These simulations were conducted using velocity models selected by GA. Observed motions at a depth of $77.45 \mathrm{~m}$ are used as input motions in the simulation program. In linear analysis the soil is assumed to be a linear inelastic material with properties controlled by small strain shear stiffness, whereas in nonlinear analysis, simulations are performed using a hyperbolic failure-seeking model that was introduced by Pyke (1979).

After each simulation, matching is performed between the simulated motion and their corresponding observed motion at the surface. For this purpose, a new proposed quantitative matching technique is presented. This matching technique consists of a successive series of equations to find a quantitative measure for the non-fitting between the simulated and observed motions (i.e. Error); see Eqs. (1) through (4).

$$
\begin{aligned}
\sigma_{i} & =\sqrt{\left(A_{i(\text { simulated })}-A_{i(\text { observed })}\right)^{2}} \\
\text { Aveg. } & =\frac{\sum_{i=1}^{\text {ndata }} \sigma_{i}}{\text { ndata }} \\
\sigma_{\text {Total }} & =\sqrt{\frac{\sum_{i=1}^{\text {ndata }}\left(\sigma_{i}-\text { Aveg. }\right)^{2}}{\text { ndata }}} \\
\text { Error } & =\text { Aveg. }+\sigma_{\text {Total }}
\end{aligned}
$$

where $A_{i \text { (simulated) }}$ and $A_{i \text { (observed) }}$ are the amplitude of the simulated and observed motions, respectively, ndata is the number of the data points in the selected time window for matching, $i$ is the time series data points starting from 1 through ndata, Error is the error in matching between ob-

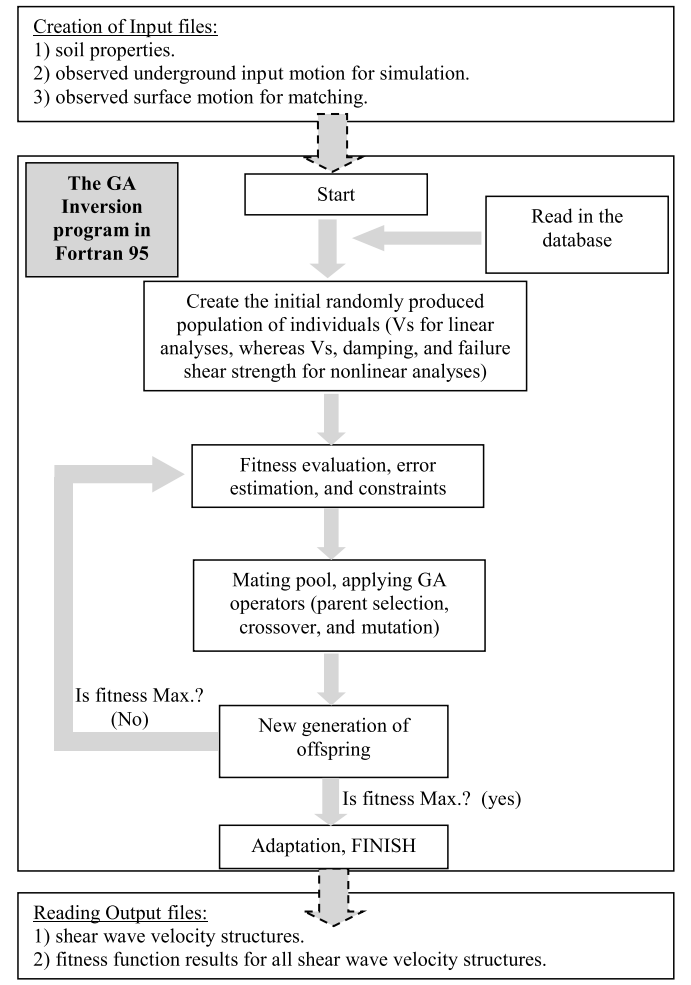

Fig. 3. Flowchart for the nonlinear GA inversion technique. The database consists of the minimum and maximum of $V_{s}$ structure and GA parameters, such as mutation and crossover probability and the string length.

served and simulated motions.

Consequently, the lesser the error in matching for a given shear wave velocity structure, the higher the fitness between the individuals. We adopted and modified the backbone 


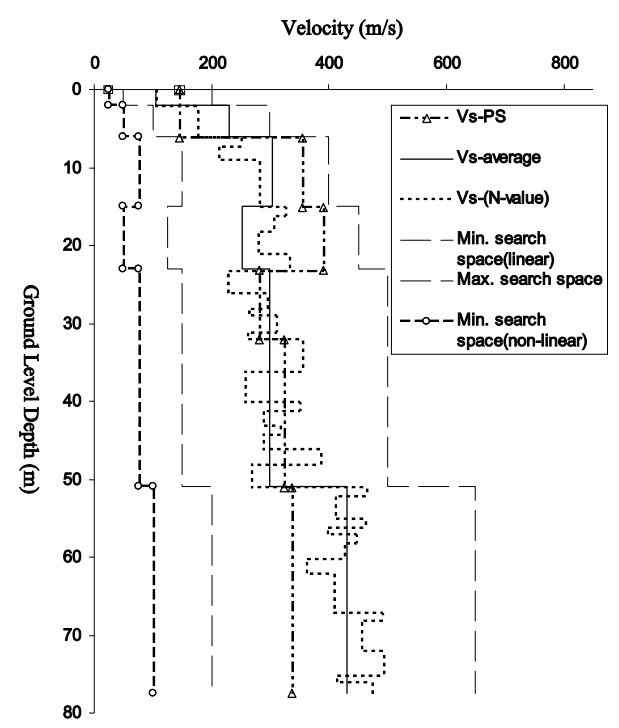

Fig. 4. Averaged initial shear wave velocity structure and the search space for GA inversion used in linear and nonlinear analyses at the Kushiro Port array site. $V_{s}$-PS and $V_{s}$-(N-value) are the shear wave velocity estimated from PS logging data and estimated empirically from the $\mathrm{N}$-value, respectively.

genetic algorithm routines from the LGADOS code placed in a public domain by Coley $(2001,2002)$. A flowchart for the nonlinear GA Inversion technique is shown, in Fig. 3.

After several trials, we concluded that the population of 100 individuals and 30 generations produce an appropriate performance of the algorithm. One individual corresponds to one simulation using one shear velocity model. In the case of linear simulations, the genes for each individual are shear wave velocities for each layer. In the case of nonlinear simulations, the genes for each individual are shear wave velocities, damping coefficients, and failure shear strength for each layer. The maximum standard deviation for the layers $(0 \sim 23 \mathrm{~m}$ depth $)$ is $64 \mathrm{~m} / \mathrm{s}$, whereas for the layers below the depth of $23 \mathrm{~m}$ it is $11 \mathrm{~m} / \mathrm{s}$. Therefore, the layers below the depth of $23 \mathrm{~m}$ are not highly responsible for the nonlinear response. It is important to note that during nonlinear simulations the velocities for these layers are fixed.

The designed search space for the linear analyses is $\pm 50 \%$ of the initial shear wave velocities, whereas the designed minimum search space for the nonlinear analyses is $75 \%$ reduced from the initial shear wave velocities for each layer, as shown in Fig. 4. The maximum search space for the nonlinear analyses is similar for that for the linear analyses because during nonlinear analyses a reduction in shear velocities is expected. This initial shear wave velocity structure was estimated based on velocities obtained empirically from the (SPT)N-value (after Thabet et al., 2007). In GA searching, the incremental value of the model parameter is variant because the values are selected stochastically and governed by the fitness function. According to typical modulus reduction and damping curves for sand at a depth of less than $100 \mathrm{~m}$ (after Seed et al., 1984), the damping factor applied in the linear analysis is equal to $1 \%$, whereas damping factors during nonlinear analysis are permitted in the range between approximately 3 and $30 \%$. For the inversion of the velocities before and after the three mainshocks,
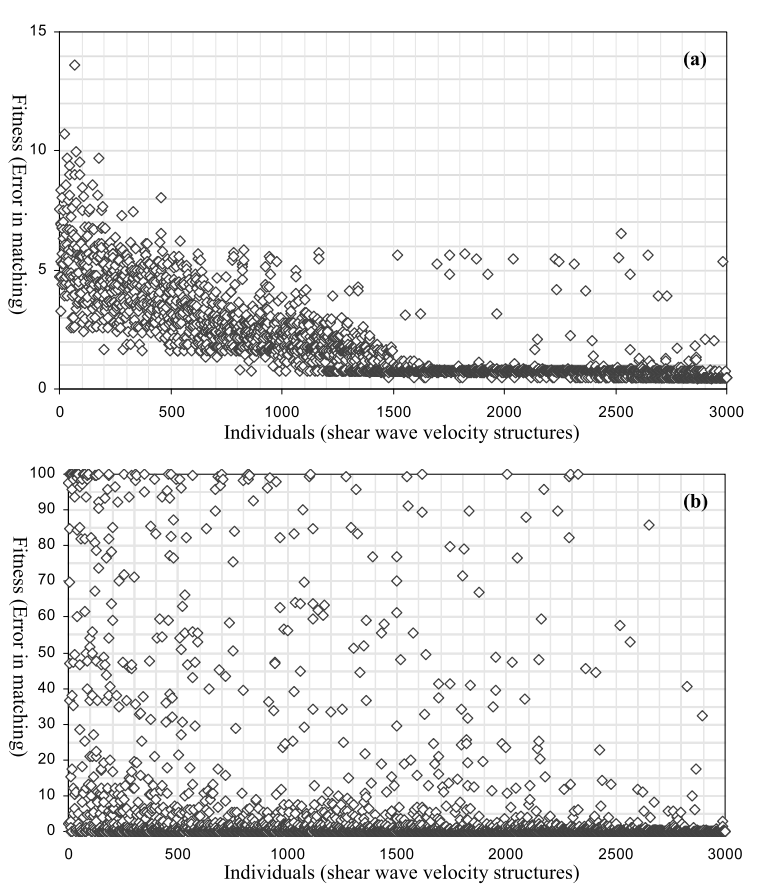

Fig. 5. Example of GA inversion performance during linear analyses using the currently proposed matching technique (a), and using the chi-square matching method (b).

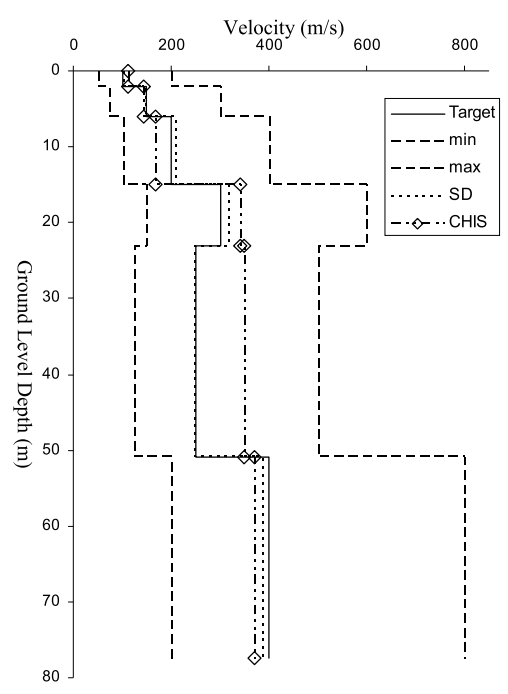

Fig. 6. Resulting shear wave velocity structures from the experimental analyses using the currently proposed matching technique (SD) and using the chi-square matching method (CHIS). Target, min and max are the target shear wave velocity, and minimum and maximum search space respectively, in the experimental analyses.

the EW and NS components are treated independently.

\section{Validation of the Analyses}

An experimental validation has been conducted to verify the reproductivity of the newly proposed nonlinear GA inversion technique. For this purpose, we used the underground NS component of the before 1993 Kushiro-Oki earthquake as an input motion to calculate the motion at the surface using assumed velocity structure. Experimentally, we consider the calculated motion at the surface and the assumed velocity structure as experimental targets. GA 


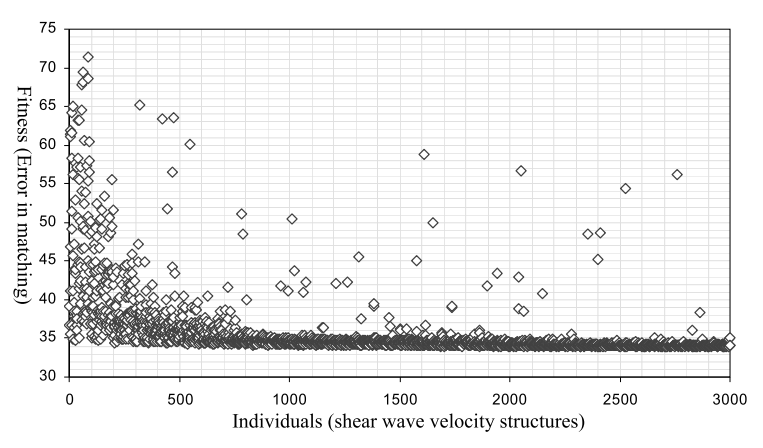

Fig. 7. Example of GA inversion performance using the current proposed matching technique during the nonlinear analyses.

inversion is then carried out to find the velocity structure that can yield $100 \%$ matching between the experimentally calculated surface motion and the simulated motions resulted from GA inversion. An example of GA inversion performance for the before mainshock event using the currently proposed matching technique and chi-square matching method is shown in Fig. 5. The highest difference between the experimental velocity structure and the resulting velocity structure from GA inversion using the current proposed matching technique is $5 \%$, whereas using the chisquare matching method, it is $40 \%$, as shown in Fig. 6.

Similar experimental analyses are conducted using nonlinear simulations. An example of the GA performance is shown in Fig. 7. The standard error using nonlinear simulations is approximately $20 \%$. This high standard error compared with those related to linear simulations can be attributed to the three unknown factors (shear velocities, damping ratio, and failure shear strength) that we are searching for in the nonlinear simulations. The results from the currently proposed nonlinear GA inversion technique are considered to be unique results for five main reasons. (1) the above-mentioned experimental analyses, (2) a direct link between the GA inversion with the FEM simulation and matching technique due to the high dependency of ground motion simulation on a reliable shear wave velocity structure, (3) limiting the shear wave velocity search space to $\pm 50 \%$ of the initial velocity model, (4) very small dispersion that resulted from the experimental validation for the inversion technique is about $\pm 5 \%$ error, (5) high consistency of the resulted shear velocities inferred from 21 before and after mainshock events for layers below at a depth $23 \mathrm{~m}$ that do not contribute to the nonlinear response.

\section{Liquefaction Detection Technique}

After the shear wave velocity structures were estimated from before and after the mainshocks, nonlinear analyses for the three mainshocks were carried out. For this purpose, each mainshock is divided into four time windows, each of which along the mainshock time series is treated as an independent ground motion. The first time window is determined based on the frequency-time representation of the mainshock motion at the surface, as shown in Fig. 8, whereas the later three time windows are determined based on the dominant peak ground accelerations with a lapse of time during each specific time window. The frequency-time

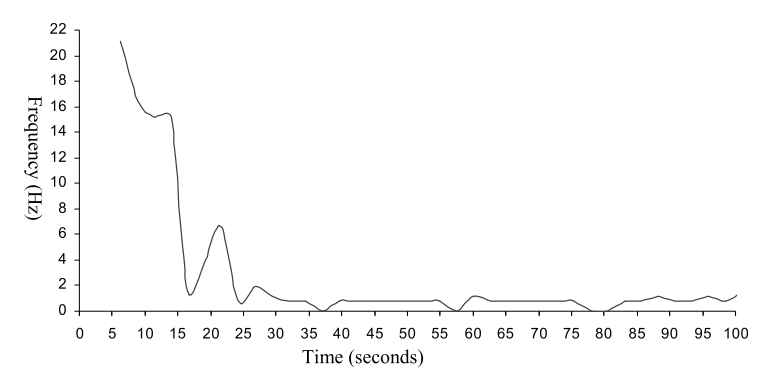

Fig. 8. Frequency-Time representation for the NS component of the 1993 Kushiro-Oki earthquake.

representation is calculated by taking the Fourier transform within a moving time window, known also as the short-time Fourier transform (STFT), which is the simplest among the variety of time-frequency representations (Qian and Chen, 1996). In the present study, the STFT computation is conducted for the mainshock horizontal acceleration records utilizing a Hanning window of length $2.56 \mathrm{~s}$. Based on the fact that the soil shows degradation behavior at strains larger than $1 \%$, a number of nonlinear simulations are carried out for each independent time window along the mainshock time series using the nonlinear GA inversion technique to set the parameters required for nonlinear analyses, such as failure shear strength and damping ratio and shear velocities for each layer. The parameters in Table 2 represent the best fit parameters in our simulations for the 1993 Kushiro-Oki earthquake. It is important to note that shear wave velocities and failure strength values of the fifth and sixth layers are fixed. We fixed these layers based on results from earlier linear analyses that showed that these layers are not highly responsible for the nonlinear response that appeared at the surface horizontal components. In order to minimize both the search space and time, the damping ratios of the layers below the depth of $23 \mathrm{~m}$ were set between 1 and $5 \%$ according to typical modulus reduction and damping curves for sand at a depth of less than $100 \mathrm{~m}$ (after Seed et al., 1984). The horizontal components observed at the $77.45 \mathrm{~m}$ depth were used as imposed motions in the simulations. The simulated motions were subsequently multiplied by weighted functions in order to eliminate the non-fitting part of the simulated motion. These weighted functions had a summation of one at any time step. Finally, stacking of the simulated weighted waveforms is applied.

\section{Results and Discussion}

Good agreement is obtained in terms of the frequency content, amplitude, and waveform between the observed and simulated motions for the 21 before and after mainshock events. An example of simulated waveforms for an after the 1994 Hokkaido Toho-Oki mainshock event that achieved the best fit with the observed motions in each of the EW and NS components is shown in Fig. 9.

The final velocity structures are shown in Fig. 10. These velocity structures represent the averaged structures for the periods before, between, and after the three mainshocks. Shear wave velocity structures from the EW and NS components can be identical only in the case of an isotropic medium, but in practical terms they are different due to het- 
Table 2. Resulted nonlinear parameters used for the 1993 Kushiro Oki earthquake. $\zeta$ and $\gamma$ are damping ratio and shear strength, respectively.

\begin{tabular}{|c|c|c|c|c|c|c|c|}
\hline \multirow[b]{2}{*}{ Time window } & \multirow[b]{2}{*}{ Depth } & \multicolumn{3}{|c|}{ EW component } & \multicolumn{3}{|c|}{ NS component } \\
\hline & & $\begin{array}{c}V_{s} \\
(\mathrm{~m} / \mathrm{s})\end{array}$ & $\begin{array}{c}\zeta \\
(\%)\end{array}$ & $\begin{array}{c}\gamma \\
(\mathrm{kPa})\end{array}$ & $\begin{array}{c}V_{s} \\
(\mathrm{~m} / \mathrm{s})\end{array}$ & $\begin{array}{c}\zeta \\
(\%)\end{array}$ & $\begin{array}{c}\gamma \\
(\mathrm{kPa})\end{array}$ \\
\hline \multirow{4}{*}{ First time window } & $2 \mathrm{~m} \sim 6 \mathrm{~m}$ & 288 & 3.3 & $9.60 \mathrm{E} 05$ & 213 & 6 & 7.04 E05 \\
\hline & $6 \mathrm{~m} \sim 15 \mathrm{~m}$ & 155 & 5 & $3.00 \mathrm{E} 05$ & 159 & 11 & $3.55 \mathrm{E} 05$ \\
\hline & $15 \mathrm{~m} \sim 23 \mathrm{~m}$ & 280 & 5 & $1.00 \mathrm{E} 06$ & 280 & 11 & $1.13 \mathrm{E} 06$ \\
\hline & $51 \mathrm{~m} \sim 77.45 \mathrm{~m}$ & 333 & 3 & $1.93 \mathrm{E} 06$ & 333 & 4 & $1.93 \mathrm{E} 06$ \\
\hline \multirow{4}{*}{ Second time window } & $0 \mathrm{~m} \sim 2 \mathrm{~m}$ & 169 & 14 & $2.79 \mathrm{E} 05$ & 156 & 12 & $2.73 \mathrm{E} 05$ \\
\hline & $2 \mathrm{~m} \sim 6 \mathrm{~m}$ & 218 & 14 & $4.94 \mathrm{E} 05$ & 181 & 12 & 3.91 E05 \\
\hline & $6 \mathrm{~m} \sim 15 \mathrm{~m}$ & 125 & 15 & $1.64 \mathrm{E} 05$ & 174 & 15 & 3.12 E05 \\
\hline & $15 \mathrm{~m} \sim 23 \mathrm{~m}$ & 143 & 15 & $2.20 \mathrm{E} 05$ & 106 & 15 & $1.19 \mathrm{E} 05$ \\
\hline \multirow{5}{*}{ Third time window } & $2 \mathrm{~m} \sim 6 \mathrm{~m}$ & 210 & 15 & $4.97 \mathrm{E} 05$ & 278 & 4 & 7.46 E05 \\
\hline & $6 \mathrm{~m} \sim 15 \mathrm{~m}$ & 108 & 15 & $1.12 \mathrm{E} 05$ & 82 & 11 & $1.28 \mathrm{E} 05$ \\
\hline & $15 \mathrm{~m} \sim 23 \mathrm{~m}$ & 100 & 15 & $9.87 \mathrm{E} 04$ & 140 & 11 & $3.83 \mathrm{E} 05$ \\
\hline & $23 \mathrm{~m} \sim 51 \mathrm{~m}$ & 280 & 2.4 & $1.40 \mathrm{E} 06$ & 280 & 3 & $1.40 \mathrm{E} 06$ \\
\hline & $51 \mathrm{~m} \sim 77.45 \mathrm{~m}$ & 333 & 2.4 & $1.93 \mathrm{E} 06$ & 333 & 3 & $1.93 \mathrm{E} 06$ \\
\hline \multirow{5}{*}{ Fourth time window } & $0 \mathrm{~m} \sim 2 \mathrm{~m}$ & 158 & 5 & $2.85 \mathrm{E} 05$ & 191 & 3 & $4.89 \mathrm{E} 05$ \\
\hline & $2 \mathrm{~m} \sim 6 \mathrm{~m}$ & 254 & 5 & $7.84 \mathrm{E} 05$ & 277 & 3 & $1.09 \mathrm{E} 06$ \\
\hline & $6 \mathrm{~m} \sim 15 \mathrm{~m}$ & 63 & 23 & $7.60 \mathrm{E} 04$ & 66 & 25 & $8.29 \mathrm{E} 04$ \\
\hline & $15 \mathrm{~m} \sim 23 \mathrm{~m}$ & 124 & 23 & $3.02 \mathrm{E} 05$ & 230 & 25 & $1.03 \mathrm{E} 06$ \\
\hline & $23 \mathrm{~m} \sim 51 \mathrm{~m}$ & 280 & 4 & $1.40 \mathrm{E} 06$ & 280 & 5 & $1.40 \mathrm{E} 06$ \\
\hline
\end{tabular}

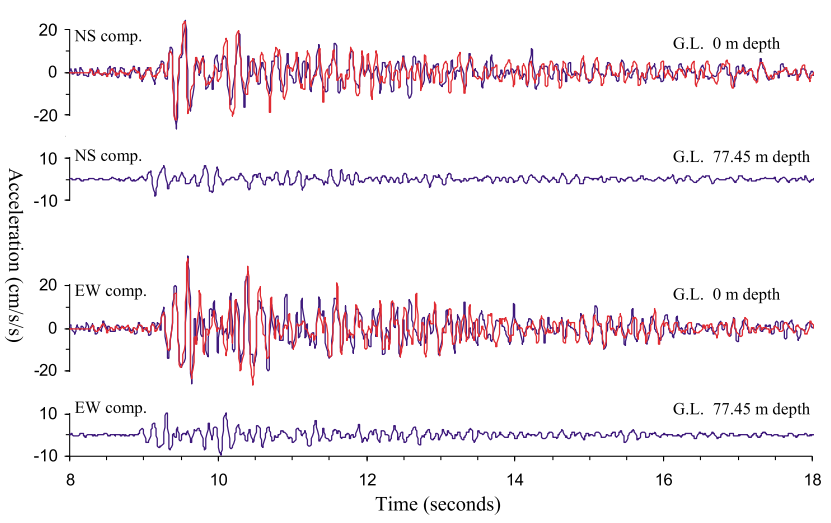

Fig. 9. Linear simulations of the 2003/9/11 04:31 acceleration records, observed (blue traces) and simulated (red traces).

erogeneity in the medium according to analyses conducted by Aguirre and Irikura (1997). Therefore, the two components are treated independently. Layers $(0 \sim 6 \mathrm{~m}$ depth $)$ show unstable variation in shear velocities before and after the 1993 Kushiro-Oki earthquake that could be assumed to be due to the consolidation recovery process that follows the nonlinear response of the mainshock. The layers (6-23 m depth) exhibit a strong suppression of shear wave velocity in both components of the aftershocks. The maximum reductions in shear velocities before and after the 1993 Kushiro-Oki and 1994 Hokkaido Toho-Oki earthquakes are 20 and $24 \%$, respectively, whereas the maximum reduction in shear velocities before and after the 2003
Tokachi-Oki is $6 \%$. The standard deviations of the differences between the velocities of before and after the three mainshocks are calculated at intervals of $0 \sim 23 \mathrm{~m}$ depth and $23 \sim 77.45 \mathrm{~m}$ depth. At $0 \sim 23 \mathrm{~m}$ depth, the maximum standard deviation is $64 \mathrm{~m} / \mathrm{s}$. At $23 \sim 77.45 \mathrm{~m}$ depth, the maximum standard deviation is $9 \mathrm{~m} / \mathrm{s}$. Shear velocities at a depth of $23 \sim 51 \mathrm{~m}$ estimated from the NS component of the 1993 Kushiro-Oki earthquake and those of a depth of $51 \sim 77.45 \mathrm{~m}$ depth that estimated from the NS component of the 1994 Hokkaido Toho-Oki earthquake and EW component of the 2003 Tokachi-Oki earthquake show an unusual maximum standard deviation of $18 \mathrm{~m} / \mathrm{s}$. This can be assumed to be due to the incompletely uniqueness of the analysis.

In the nonlinear analyses, the resultant waveforms are in strong agreement with the observation in the designed time windows. An example of the nonlinear simulations for the 1993 Kushiro-Oki earthquake with their corresponding time windows is shown in Fig. 11. From the STFT computation and from the nonlinear analysis that was carried out, we could assume that the first time window shows the starting point for the liquefaction, whereas the second and third time windows are the most influenced by the liquefaction. The misfit that appears outside the designed time windows is natural because the present nonlinear constitutive model that was introduced by Pyke (1979) does not account for liquefaction effects. This nonlinear constitutive model is shown in Eq. (5).

$$
\begin{aligned}
\tau-\tau_{\mathrm{c}} & =G_{\max } \cdot \frac{\left(\gamma-\gamma_{\mathrm{c}}\right)}{\left(1+\left(\gamma-\gamma_{\mathrm{c}}\right) /\left(C \cdot \gamma_{\mathrm{ref}}\right)\right)} \\
C & =1-\tau_{\mathrm{c}} / S_{\mathrm{u}} ; \quad \gamma_{\mathrm{ref}}=S_{\mathrm{u}} / G_{\max }
\end{aligned}
$$



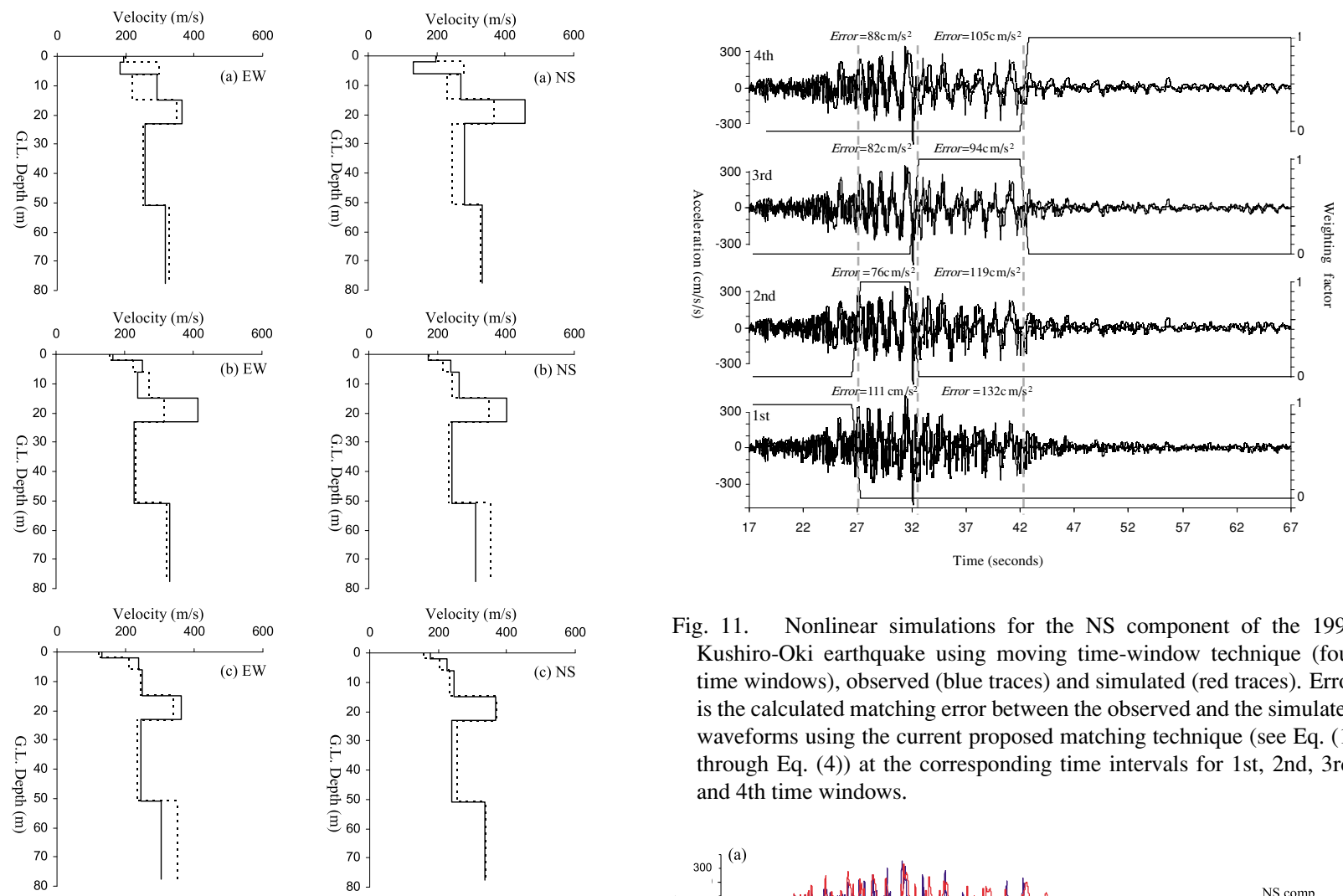

Fig. 11. Nonlinear simulations for the NS component of the 1993 Kushiro-Oki earthquake using moving time-window technique (four time windows), observed (blue traces) and simulated (red traces). Error is the calculated matching error between the observed and the simulated waveforms using the current proposed matching technique (see Eq. (1) through Eq. (4)) at the corresponding time intervals for 1st, 2nd, 3rd, and 4 th time windows.

Fig. 10. Shear velocity structures before (continuous traces) and after (dashed traces) the (a) 1993 Kushiro-Oki, (b) 1994 Hokkaido Toho-Oki and (c) 2003 Tokachi-Oki earthquakes.

where $\tau$ is the shear stress, $G_{\max }$ is the maximum shear modulus, $\gamma$ is the shear strain, $\tau_{\mathrm{c}}$ and $\gamma_{\mathrm{c}}$ are the values of the shear stress and shear strain at load reversal, respectively, $C$ and $\gamma_{\text {ref }}$ are parameters controlling the failure-seeking component, and $S_{\mathrm{u}}$ is failure shear strength.

Based on these results, we propose a new technique to account for liquefaction effects and to overcome the misfit along the mainshock time series. Stacking of the simulated weighted waveforms leads to the results shown in Fig. 12, which show excellent agreement with the observations. It is important to note that when the linear or nonlinear simulations are carried out, the resulting simulated waveforms represent the overall response of the entire analyzed lithological column. For example, the predominant periods of the entire lithological column that are shown in Table 2 are $1.2 \mathrm{~s}, 1.3 \mathrm{~s}, 1.5 \mathrm{~s}$ and $1.7 \mathrm{~s}$ for the first, second, third and forth time windows, respectively. Therefore, the shallower layers whose thicknesses are thinner than $10 \mathrm{~m}$ can be resolved but included in the entire analyzed lithological column. The analyzed seismic phases in this study are considered to be $S$-waves. A similar assumption was made Aguirre and Irikura (1997) when they analyzed ground motion records of the 1995 Hyogo-ken Nambu earthquake at Port Island vertical array site.

Kokusho and Matsumoto (1998) concluded that damping ratios for the 1995 Hyogo-ken Nambu earthquake are evidently larger than those for the aftershocks. Results obtained by Pease and O'Rourke (1997) from investigations on the seismic response at Treasure Island during the
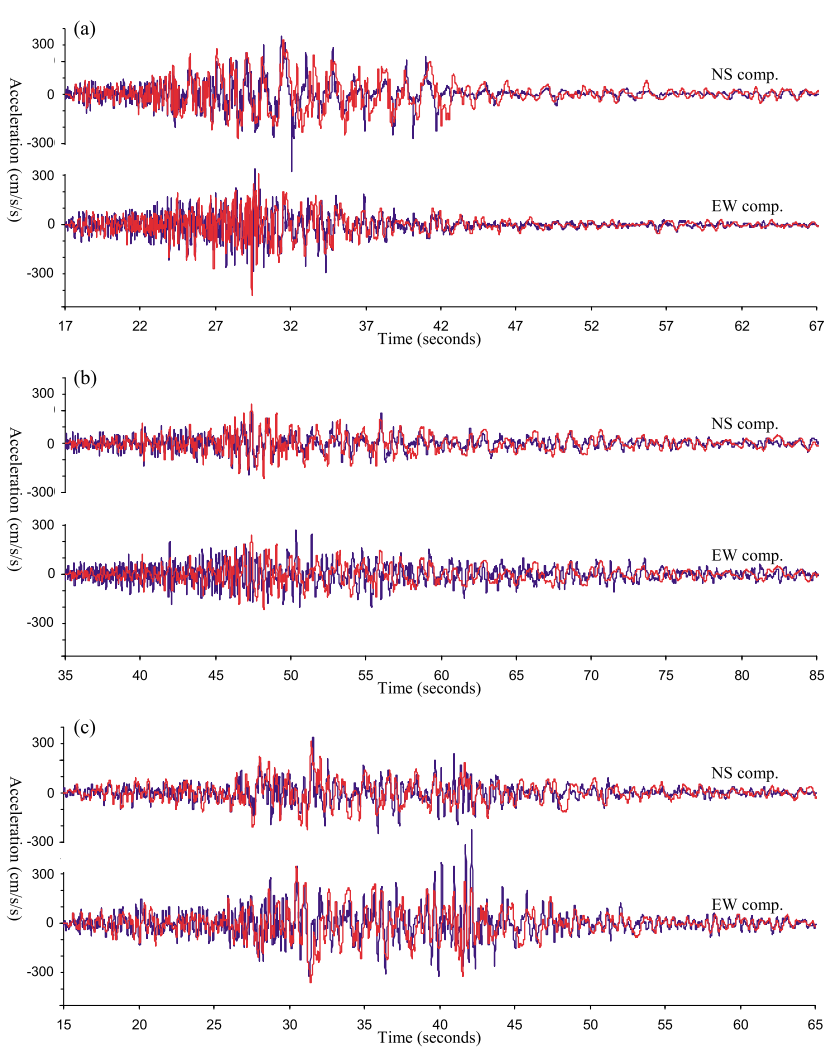

Fig. 12. Nonlinear simulations at Kushiro Port site $(0 \mathrm{~m}$ depth $)$ for the (a) 1993 Kushiro-Oki, (b) 1994 Hokkaido Toho-Oki, and (c) 2003 Tokachi-Oki earthquakes, observed (blue traces) and simulated (red traces).

1989 Loma Prieta earthquake $\left(M_{\mathrm{w}}=6.9\right)$ also show that the character of the stress-strain curve drops abruptly after the first $12 \mathrm{~s}$. The present study shows similar results to those obtained by previous researchers in terms of stiffness degradation phenomena that occurs during the liquefaction- 


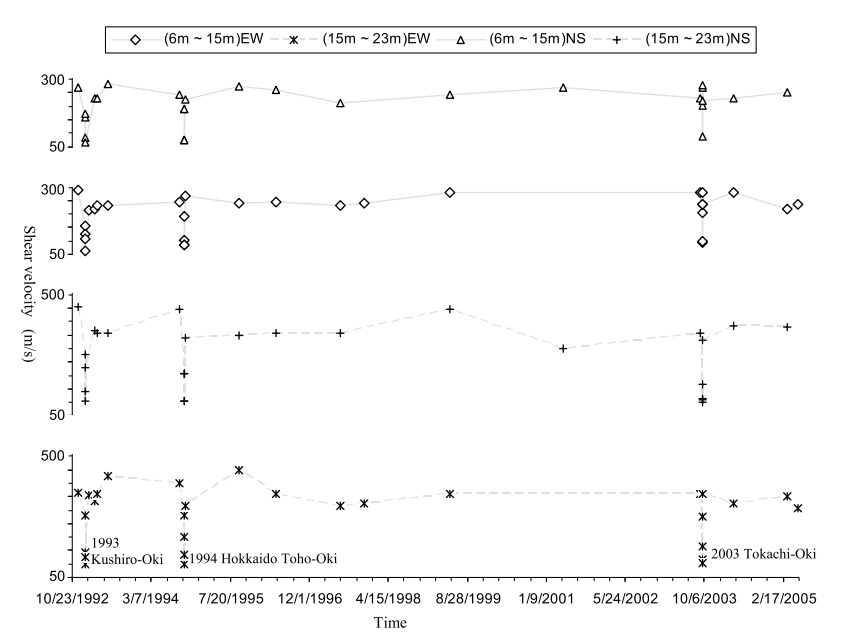

Fig. 13. Schematic representation of the velocity variation at Kushiro Port array site using linear analyses inferred from EW and NS components for the third and fourth layers. Shear velocities estimated during nonlinear analyses have been included for reliable comparison along the velocity variation history.

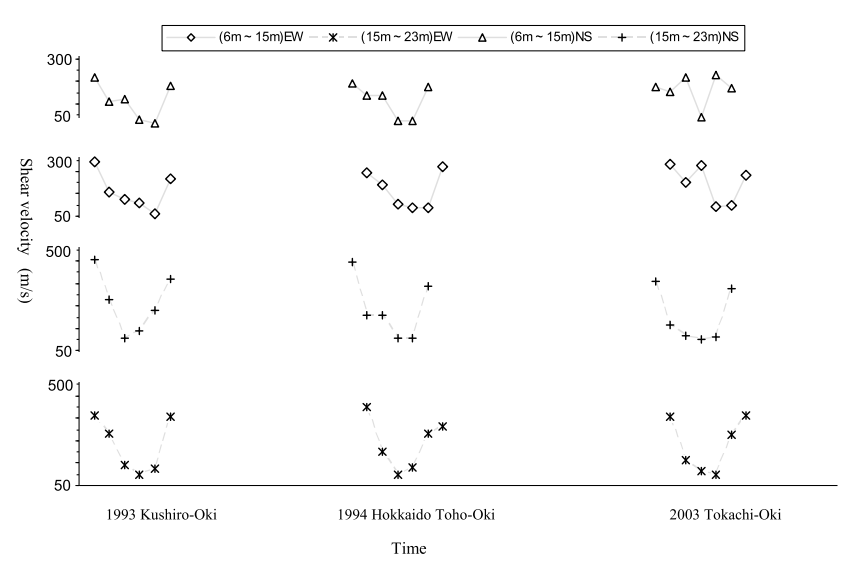

Fig. 14. Schematic representation of the velocity variation at Kushiro Port array site using nonlinear analyses inferred from EW and NS components for the third and fourth layers. It is important to note that the two shear velocity values at the boundary of each curve represent the velocities estimated from two events before and after each mainshock.

induced nonlinear response.

In Figs. 13 and 14, shear velocity variations using linear and nonlinear analyses at Kushiro Port for the layers $(6 \sim$ $15 \mathrm{~m}$ depth and $15 \sim 23 \mathrm{~m}$ depth) show temporarily strong velocity reduction during the three strong ground motions. The velocity variation before, during, and after the three strong motions follows the same tendency as the curve of consolidation shown by Terzaghi (1956).

Although the 2003 Tokachi-Oki earthquake has higher PGA at $77.45 \mathrm{~m}$ and shortest epicenter distance compared with the 1994 Hokkaido Toho-Oki earthquake, weak degree of liquefaction appears in the 2003 Tokachi-Oki earthquake, whereas high degree of liquefaction appears in the 1994 Hokkaido Toho-Oki earthquake. As shown in Fig. 10, the shear wave velocity of the fourth layer is highly reduced after the 1993 Kushiro-Oki earthquake and the 1994 Hokkaido Toho-Oki earthquake, whereas after the 2003

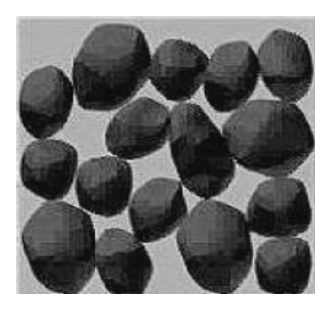

a) Water-saturated sand grains
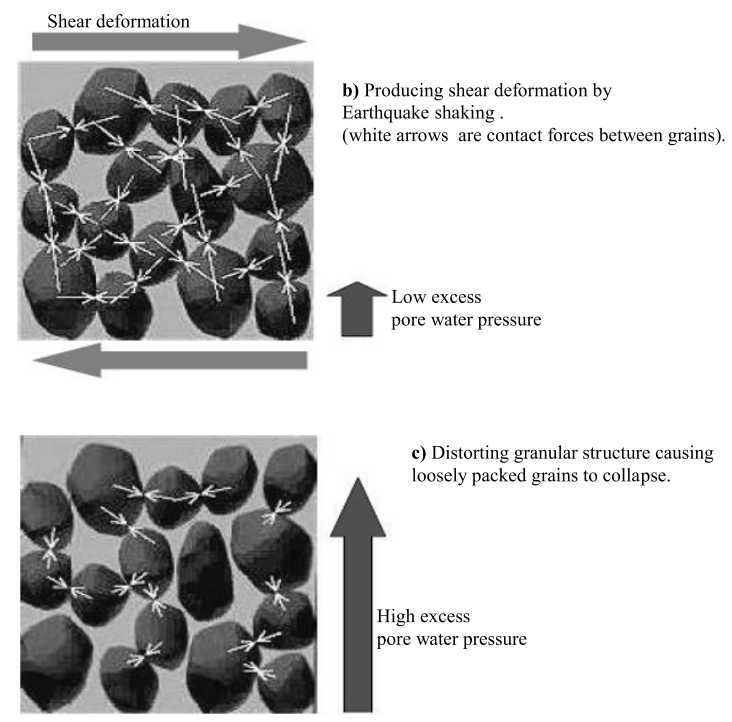

Fig. 15. Schematic representation for liquefaction mechanism in water-saturated sand.

Tokachi-Oki earthquake is slightly reduced. The maximum reductions in shear velocities before and after the 1993 Kushiro-Oki and 1994 Hokkaido Toho-Oki earthquakes are $20 \%$ and $24 \%$, respectively, whereas the maximum reduction in shear velocities before and after the 2003 TokachiOki is $6 \%$. This could be attributed to the high increase in rigidity along 9 years (i.e. period between the 1994 Hokkaido Toho-Oki earthquake and the 2003 Tokachi-Oki earthquake).

\section{Conclusions}

According to previous studies conducted by Kostadinov and Yamazaki (2001) and with the results of our STFT analysis for the observed horizontal ground motions, liquefaction can occur during the mainshocks due to abrupt changes in the predominant frequency. Liquefaction is a process by which sediments below the water table temporarily lose strength gradually and behave as a viscous liquid rather than as a solid, as shown in Fig. 15. We have studied this variation process in stiffness due to the influence of liquefaction by means of a newly proposed nonlinear GA inversion technique applied on records before, during and after the 1993 Kushiro-Oki, 1994 Hokkaido Toho-Oki and the 2003 Tokachi-Oki earthquakes in Hokkaido, Japan. Based on the results of this study, the following conclusions are derived:

1. The proposed inversion technique is more efficient in terms of its estimation ability for shear velocities.

2. Layers (6-23 m depth) exhibited strong reduction in shear velocities during the three successive mainshocks. 
3. Stiffness degradation could be evaluated during mainshocks by means of nonlinear GA inversion and then applying moving time-window weighted functions to the nonlinearly simulated waveforms. In this regard, each mainshock is considered to consist of several time-windows. Consequently, each timewindow is considered as an independent motion and has its own nonlinear stiffness parameters.

4. High increase of rigidity following a trend that resembles a consolidation curve could be seen after the 1994 Hokkaido Toho-Oki earthquake. Therefore, a weak degree of liquefaction appears in the 2003 Tokachi-Oki earthquake.

It is hoped that this study will draw increased attention to this topic so as to improve current understanding.

Acknowledgments. The authors are grateful to Prof. Susumu Iai of Kyoto University and to Dr. Atsushi Nozu of the Port and Airport Research Institute for their kind arrangement of the geophysical and geotechnical underground structures. The authors would like to thank Professor Satoshi Kaneshima and the two anonymous reviewers for the valuable suggestions on the earlier version of the manuscript.

\section{References}

Aguirre, J. and K. Irikura, Nonlinearity, Liquefaction, and velocity variation of soft soil layers in Port Isalnd, Kobe, during the Hyogo-ken Nanbu Earthquake, Bull. Seismol. Soc. Am., 87, 1244-1258, 1997.

Coley, D. A., An Introduction to Genetic Algorithms for Scientists and Engineers, World Scietific, 2001.

Coley, D. A., David Coley's GA: http://www.ex.ac.uk/cee/ga/software. htm, 2002.

Koketsu, K., K. Hikima, S. Miyazaki, and S. Ide, Joint Inversion of Strong Motion and Geodetic Data for the Source Process of the 2003 Tokachioki, Hokkaido, Earthq., Earth Planets Space, 55, 1-6, 2003.
Kokusho, T. and M. Matsumoto, Nonlinearity in site amplification and soil properties during the 1995 Hyogo-Ken Nanbu Earthquake, Special Issue of Soils and Foundations, Japanese Geotechnical Society, 1-9, Sept. 1998.

Kostadinov, M. and F. Yamazaki, Detection of soil liquefaction from strong motion records, Earthq. Eng. Struct. Dyn., 173-193, 2001.

Miyajima, M., M. Kitaura, and S. Nozu, Detective method of liquefaction using strong ground motion records, Proceedings of the $3^{\text {rd }}$ ChinaJapan-US Trilateral Symposium on Lifeline Earthquake Engineering, Kunming, China, 133-140, August 1998.

Nakayama, W., Y. Shimizu, and T. Suzuki, A new method to detect subsoil liquefaction using seismic records, Proceedings of the $53^{\text {rd }}$ Annual Conference of Japanese Society of Civil Engineers, vol. 1-B. JSCE, 862-863, 1998 (in Japanese).

Ozaki, R., Study on real-time earthquake mitigation liquefaction monitoring and earthquake countermeasures, $\mathrm{PhD}$ Thesis, Kobe University, 1999 (in Japanese).

Pease, J. W. and T. D. O'Rourke, Seismic response of liquefaction sites, $J$. Geotech. Geoenviron. Eng., 123, 37-45, 1997.

Pestana, J. M. and F. Nadim, AMPLE2000 A computer program for analysis of amplification of earthquakes, Geotechnical Engng. Report No. $U C B / G T / 2000-04$, Department of Civil \& Environ. Engineering, University of California, Berkeley, 2000.

Pyke, R., Non-linear soil models for irregular cyclic loadings, J. Geotech. Eng. Div., ASCE, 105(GT6), 715-726, 1979.

Qian, Sh. and D. Chen, Joint Time-Frequency Analysis: Methods and Applications, Prentice-Hall PTR: Upper Saddle River, NJ, 1996.

Seed, H. B., R. T. Wong, E. M. Idriss, and K. Tokimatsu, Moduli and Damping Factors for Dymanic Analyses of Cohesionless Soils, Report No. UCB/EERC-84/11, Erathquake Engineering Research Center, University of California, Berkeley, 1984.

Terzaghi, K., Theoretical Soil Mechanics, Wiley, New York, 1956.

Thabet, M., H. Nemoto, and K. Nakagawa, Reliability of shear wave velocity models inferred from linear site response analyses using log data, J. Geosci., Osaka City Univ., 50, Art. 9, p. 107-123, March 2007.

M. Thabet (e-mail: mostafa@sci.osaka-cu.ac.jp), H. Nemoto, and K. Nakagawa 